\title{
A Simple Annulus Power Balance in EBT-I
}

\author{
S. K. Borowski \\ N. A. Uckan \\ E. F. Jaeger \\ T. Kammash
}

\section{MASTER}

\section{OAK RIDGE NATIONAL LABORATORY} OPERATED BY UNION CARBIDE CORPORATION - FOR THE DEPARTMENT OF ENERGY 


\section{Printed in the United States of America Avallable from National Technical Information Service \\ U S Department of Commerce 5285 Port Royal Road, Sprıngfıeld, Vırgınıa 22161 \\ Price Printed Copy $\$ 450$, Microfiche $\$ 300$}

This report was prepared as an account of work sponsored by an agency of the United States Government Neither the United States Government nor any agency thereof, nor any of their employees, contractors, subcontractors, or their employees, makes any warranty, express or implied, nor assumes any legal liability or responsibility for any third party's use or the results of such use of any information, apparatus, product or process disclosed in this report nor represents that its use by such third party would not infringe privately owned rights 


\section{DISCLAIMER}

This report was prepared as an account of work sponsored by an agency of the United States Government. Neither the United States Government nor any agency Thereof, nor any of their employees, makes any warranty, express or implied, or assumes any legal liability or responsibility for the accuracy, completeness, or usefulness of any information, apparatus, product, or process disclosed, or represents that its use would not infringe privately owned rights. Reference herein to any specific commercial product, process, or service by trade name, trademark, manufacturer, or otherwise does not necessarily constitute or imply its endorsement, recommendation, or favoring by the United States Government or any agency thereof. The views and opinions of authors expressed herein do not necessarily state or reflect those of the United States Government or any agency thereof. 


\section{DISCLAIMER}

Portions of this document may be illegible in electronic image products. Images are produced from the best available original document. 
ORNL/TM-6910

Dist. Category UC-20 a, d, g

Contract No. W-7405-eng-26

FUSION ENERGY DIVISION

A SIMPLE ANNULUS POWER BALANCE IN EBT-I

S. K. Borowski

University of Michigan, Ann Arbor, Michigan

N. A. Uckan

E. F. Jaeger

T. Kammash

University of Michigan, Ann Arbor, Michigan

Date Published - September 1979

NOTICE This document contains information of a preliminary nature. It is subject to revision or correction and therefore does not represent a final report.

Prepared by the OAK RIDGE NATIONAL LABORATORY Oak Ridge, Tennessee 37830

operated by UNION CARBIDE CORPORATION for the DEPARTMENT OF ENERGY

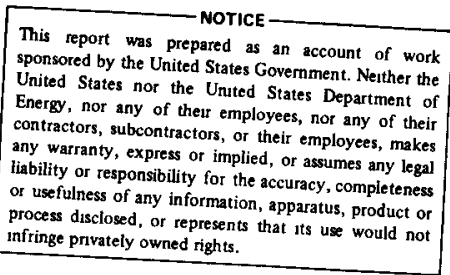

sponsored by the prepared as an account of work United States nor the Unis Government. Neither the Energy, not any of them emplates Department of any wers, subcontractors, or their employees, makes liability or responsibility impied, or assumes any legal proseculness of any informatio infringe privately owned rights. 


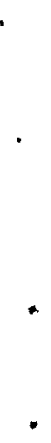




\section{CONTENTS}

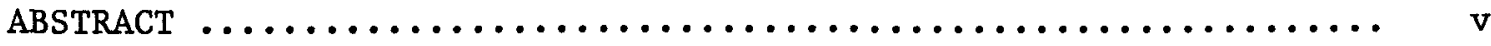

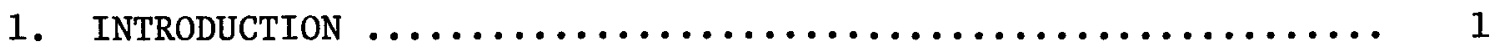

2. A REVIEW OF ELMO AND EBT-I ANNULUS PARAMETERS ............ 3

3. DRAG COOLING OF THE RELATIVISTIC ELECTRON ANNULUS .......... 7

3.1 A Binary Collision Model for Drag Cooling ........... 7

3.2 Application of Drag Cooling Model to EBT-I Data ........ 10

4. ANNULUS MICROWAVE POWER SCALING ..................... 13

5. APPLICATIONS AND DISCUSSION ......................... 17

5.1 Comparison of Theory to ELMO and EBT-I ............. 17

5.2 Scaling Projections for EBT-S .................... 21

ACKNOWLEDGMENTS ....................................... 24

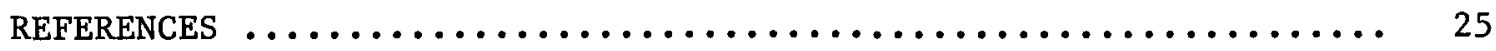

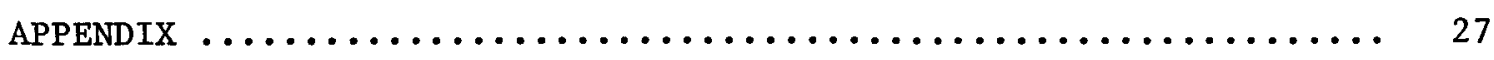


An essential feature of the ELMO Bumpy Torus (EBT) concept is the presence of a relativistic electron annulus in each of the toroidal mirror sectors. These high beta annuli are formed and sustained by microwave heating and are of sufficient density and temperature that diamagnetic currents produce the necessary minimum in the magnetic field required for MHD stability of the toroidal core plasma. Because electron rings play an important role in confinement characteristics and performance of EBT, the trade-off between the quality of the confinement afforded by the rings and the power required to sustain the rings represents an important problem in a fusion reactor. A power balance for the rings that includes drag cooling, in addition to the radiation (synchrotron and bremsstrahlung) and annulus electron-electron scattering losses, indicates that drag dominates the annulus energy balance in EBT-I. Drag cooling of the relativistic annulus electrons on the toroidal core plasma appears to provide a reasonable explanation for the decrease in the annulus electron temperature in going from ELMO to EBT-I. Theoretical estimates of the microwave power required to sustain the annulus are found to be within a factor of 2 of the experimentally determined value. Scaling projections that are shown for both EBT-I and EBT-S enable one to examine the sensitivity of the annulus electron temperature as a function of core plasma density for various microwave power levels. The results are found to be sensitive to the details of the hot electron distribution function as well as geometric and scaling parameters. Improvements to the model are under way in order to increase its capability and accuracy in assessing the overall power balance. 


\section{INTRODUCTION}

An essential feature of the ELMO Bumpy Torus (EBT) concept is the presence of a high beta (ratio of plasma pressure to magnetic pressure), relativistic electron annulus in each of the toroidal mirror sectors. These high beta annuli, formed near the mirror midplane and sustained by microwave heating, are of sufficient energy density to produce the necessary minimum in the magnetic field required for MHD stability of the toroidal core plasma. ${ }^{1,2}$ Stability of the electron ring itself requires the presence of an appreciable cold electron density component $\left(\mathrm{n}_{\mathrm{cold}} / \mathrm{n}_{\text {hot }}>1\right)$, and its diamagnetic properties are a sensitive function of the stored perpendicular energy $\left(W_{\perp}\right)$ in the annulus. ${ }^{1,2}$

Experimental and theoretical ${ }^{3}$ evidence indicates a critical range of annular beta $\left(\beta_{A} \cong 5-15 \%\right)$ separating quiet and fluctuating modes of operation. The cold or C-mode with a relatively high level of density fluctuations is observed when insufficient microwave power is supplied to produce substantial annular beta $\left(\beta_{\text {crit }}^{A} \lesssim 5 \%\right)$. At $\beta_{A} \gtrsim 15 \%$, theory predicts that the relativistic electron annuli have sufficient pressure to appropriately modify the vacuum magnetic field gradient. It is around this value of annular beta that a transition occurs from the noisy $\mathrm{C}$-mode to the quiet $\mathrm{T}$-mode possessing a substantial toroidal core plasma. The T-mode has been the subject of considerable theoretical and modeling efforts. Present understanding of equilibrium, stability, and transport in EBT-I has suggested a sequence of EBT devices aimed at addressing important physics questions, while simultaneously determining the suitability of the EBT toroidal plasma as a possible environment for controlled thermonuclear fusion reactions. ${ }^{4}$

Because the relativistic electron annuli are an integral component of the EBT concept, it is desirable to establish firm scaling for the annular plasma. While electron rings have been routinely produced in both the ELMO and EBT-I experiments, a significant difference in the annulus electron temperature has been observed between the two devices. This difference in temperature has previously been attributed to the canted configuration of the individual EBT mirror sectors and the resulting displacement of drift surfaces toward the walls of the device. 5 
In this paper we propose a possible alternative energy loss mechanism, core drag, and present theoretical estimates of the microwave power requirements necessary to sustain the stabilizing annuli when this loss mechanism is taken into account. Our calculations indicate that drag cooling of the relativistic annulus electrons on the toroidal core plasma appears to provide a reasonable explanation for the observed decrease in the annulus electron temperature in going from ELMO to EBT-I.

Covered in Sect. 2 of this paper is a review of previously reported annulus parameters for both ELMO and EBT-I, with a discussion of the discrepancy which exists between those theoretical estimates which neglect drag and the experimentally determined annulus microwave power. The slowing down of relativistic electrons in a plasma is outlined and analyzed in Sect. 3. Scaling for the power required to sustain the annulus is presented in sect. 4; here, a power balance for the rings is formulated, including drag cooling in addition to the usual synchrotron radiation and annulus scattering losses. The results obtained indicate that it is drag which dominates the annulus energy balance in EBT-I. Our theoretical estimates of the microwave power requirements are within a factor of 2 of the experimentally observed value. Finally, in Sect. 5 scaling projections are presented for both EBT-I and EBT-S, which show the annulus electron temperature variation as a function of core plasma density for given microwave power levels. A range of annular beta values between $15-30 \%$ appears achievable for projected EBT-S toroida1 plasma parameters if the microwave power levels are in the range of ح10-15 kW. 


\section{A REVIEW OF ELMO AND EBT-I ANNULUS PARAMETERS}

To set the stage for our discussion of drag as an important energy loss mechanism, we review and compare some of the annulus parameters measured on EBT-I and its progenitor, ELMO. These parameters are summarized in Table 2.1 .

The original ELMO device ${ }^{6}$ produced a stable, steady state, high beta, relativistic electron plasma having $\mathrm{kT}_{\mathrm{A}} \sim 700 \mathrm{keV}-1 \mathrm{MeV}, \mathrm{n}_{\mathrm{A}}$ $3-5 \times 10^{11} / \mathrm{cm}^{3}, \beta_{A} \sim 40-50 \%$, and stored energies $\left(W_{\perp}\right)$ ranging from v150-360 J. These energies were contained almost entirely in an annular plasma belt varying in volume between 2-3 1iters. ${ }^{7}$ Estimates of the annulus size included an $11-\mathrm{cm}$ outer radius, $7-\mathrm{cm}$ inner radius at the mirror midplane, and an axial length of $\sim 25 \mathrm{~cm} .{ }^{8}$ In such a configuration, the interior colder plasma particles, both electrons and ions, quickly drifted out the ends of the device along the magnetic field lines. Nevertheless, steady state operation was achieved by utilizing a continual flow of gas into the device, which provided both positive ion neutralization of the hot electron plasma and the cold plasma component

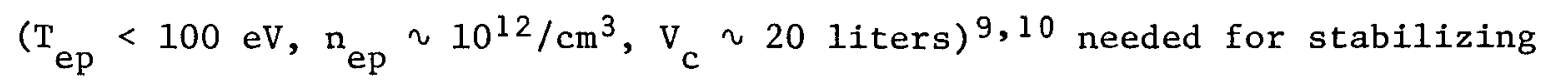
the annulus.

Despite the success of storing large energy densities in the electron annulus, most of the incident microwave energy was carried out of ELMO with the poorly confined cold plasma. These results prompted Dandl and co-workers $^{6}$ to consider a high beta, bumpy torus (EBT-I) consisting of a series of linked, canted mirrors. In such a device, the particles lost out of one mirror would pass into the adjoining section, thereby forming a circulating toroidal plasma. Both high core densities and ion temperatures would be expected from the improved confinement and ion energy gain from the microwave heated electrons. The field modification necessary to stabilize the less energetic core plasma would be provided by the high beta electron annuli which would be partially immersed in the toroidally confined plasma. ${ }^{6}$

Regarding the microwave power required to sustain the annulus, Ref. 5 considers major energy losses in both ELMO and the canted mirror facility to be Coulomb scattering of the relativistic electrons and 
Table 2.1. Experimentally measured annulus parameters

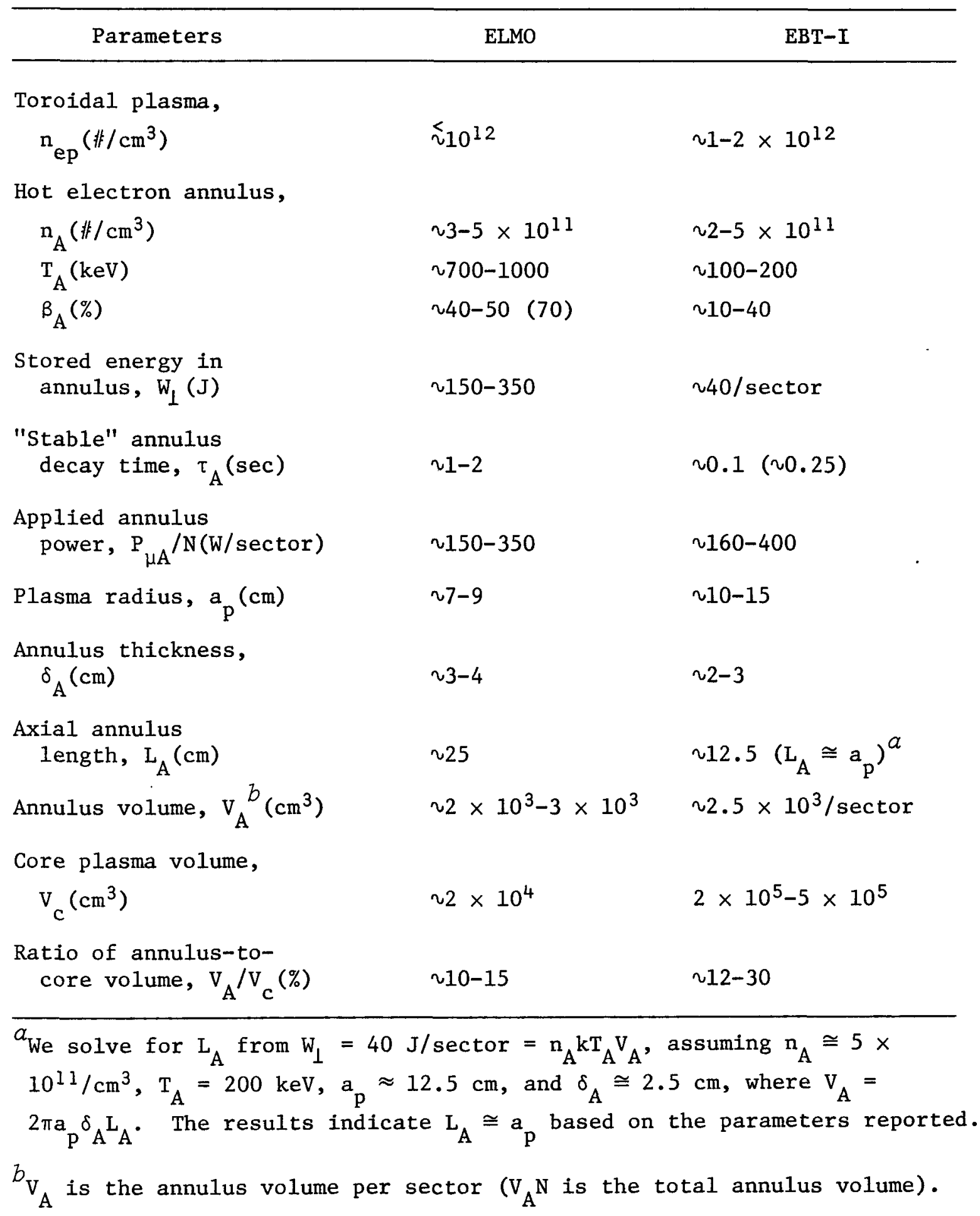


synchrotron radiation. Because roughly $400 \mathrm{~W}$ was required to sustain the annulus in ELMO at $8.5 \mathrm{kG}$, it was estimated ${ }^{5}$ that each sector of the similar size EBT device at $6 \mathrm{kG}$ would require $(6 / 8.5)^{4} 400 \mathrm{~W} \cong 100 \mathrm{~W}$ (for $P_{\text {loss }} \propto B^{4}$ ). For the full 24-sector EBT-I experiment, this meant a total power input to the rings of $2.4 \mathrm{~kW}$. Actual experimental estimates on EBT-I have shown, however, that this value is low by a factor of 4.2 From diamagnetic measurements of $W_{1} \cong 40 \mathrm{~J} /$ sector $)$ and observations of the stable decay time following a reduction in the microwave power $\left(\tau_{A} \cong 0.1 \mathrm{sec}\right)$, it has been estimated that

$$
P_{\mu \mathrm{A}}=\frac{40 \mathrm{~J} / \text { sector }}{0.1 \mathrm{sec}} \times 24 \text { sectors }=9.6 \mathrm{~kW}
$$

To estimate which of the above loss mechanisms is responsible for this large power drain ( $26 \%$ of the applied power in EBT-I), it is instructive to evaluate each one separately. Assuming a steady state, the microwave power necessary to compensate for losses due to radiation (synchrotron and bremsstrahlung) and annulus electron-electron scattering losses can be expressed as follows in mks units:

$$
\begin{aligned}
P_{\mu A} & =\left[6.2 \times 10^{-17}{ }_{B}^{2} n_{A} T_{A}\left(1+\frac{T_{A}}{204}\right)+5.35 \times 10^{-37} n_{A}^{2} T_{A}^{1 / 2}\right. \\
& \left.+5.0 \times 10^{-31} \frac{n_{A}^{2}}{T_{A}^{1 / 2}}\right] V_{A},
\end{aligned}
$$

where $\mathrm{T}$ is in $\mathrm{keV}$ and $\mathrm{V}_{\mathrm{A}} \mathrm{N}$ represents the total annulus volume. Using $\mathrm{n}_{\mathrm{A}} \cong 5 \times 10^{17} / \mathrm{m}^{3}, \mathrm{~T}_{\mathrm{A}}=200 \mathrm{keV}, \mathrm{B}\left({\Theta \mathrm{f}_{\mu \mathrm{p}}}=10.6 \mathrm{GHz}\right)=0.38 \mathrm{~T}$, and $\mathrm{V}_{A} \mathrm{~N} \cong$ $0.06 \mathrm{~m}^{3}$, one obtains

$$
P_{\mu A}=\left(2.49 \frac{\mathrm{kW}}{\mathrm{m}^{3}}+1.9 \times 10^{-3} \frac{\mathrm{kW}}{\mathrm{m}^{3}}+8.84 \frac{\mathrm{kW}}{\mathrm{m}^{3}}\right) 0.06 \mathrm{~m}^{3} \cong 0.6 \mathrm{~kW}
$$

which is more than an order of magnitude less than the observed power requirements. Clearly, an additional loss mechanism must be present. 


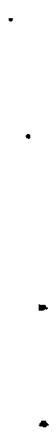




\section{DRAG COOLING OF THE RELATIVISTIC ELECTRON ANNULUS}

As we have seen in the previous section, losses due to radiation (synchrotron and bremsstrahlung) and scattering collisions between ring electrons do not account for the power required to sustain the annulus in EBT-I. However, if the energy transfer between the hot annulus electrons and the plasma electrons via Coulomb collisional drag is included, the theoretical decay time for the annulus electrons is within a factor of $\sim 2$ of the experimentally determined decay time.

In the evolution of the ELMO Bumpy Torus concept from the single mirror ELMO experiment to the full torus EBT-I device, increased core plasma densities have been achieved. With further density increases expected as larger magnetic field strengths and microwave sources become available, we anticipate enhanced Coulomb coupling between the electron rings and the toroidal core plasma and lower ring temperatures for a fixed power. Because core and annulus stability require minimum values for annular beta $\left(\beta_{A} \sim 5-15 \%\right)$ and core plasma density $\left(n_{\text {cold }} / n_{\text {hot }}>1\right)$, increased magnetic field strengths require increased microwave power to maintain the rings at a sufficiently high temperature.

\subsection{A Binary Collision Model for Drag Cooling}

A lower limit of the microwave power required to sustain the annulus against drag cooling can be obtained from the binary collision model of Kammash and Gailbraith,11,12 which describes the slowing down of relativistic electrons in a Maxwellian plasma. The rate of energy loss for relativistic "test" electrons of energy $\mathrm{E}$ in a plasma is given to lowest order in $\left(\mathrm{kT}_{\mathrm{ep}} / \mathrm{m}_{\mathrm{e}} \mathrm{c}^{2}\right)$ by the following equation in cgs units:

$\frac{d E}{d t} \cong \frac{-2 \pi e^{4} n_{e p}}{m_{e} \sqrt{\gamma+1}}\left(\frac{m_{e}}{k T_{e p}}\right)^{1 / 2} \ln \left(\frac{\hbar \omega_{p e}}{k T_{e p}}\right)^{2}\left[\gamma^{2} \frac{\Phi(R)}{R}-\frac{2 \sqrt{2(\gamma+1)}}{\sqrt{\pi}} e^{-R^{2}}\right]$,

where 


$$
\begin{aligned}
& \gamma=\frac{1}{\sqrt{1-\frac{v^{2}}{c^{2}}}}=1+\frac{\mathrm{kT}_{A}}{\mathrm{~m}_{\mathrm{e}} \mathrm{c}^{2}}, \\
& R \equiv \sqrt{\frac{\mathrm{m}_{\mathrm{e}}^{\mathrm{c}^{2}}}{\mathrm{kT}}(\gamma-1)}=\sqrt{\frac{\mathrm{T}_{\mathrm{A}}}{\mathrm{T}_{\mathrm{ep}}}},
\end{aligned}
$$

and

$$
\Phi(R)=\frac{2}{\sqrt{\pi}} \int_{0}^{R} e^{-t^{2}} d t
$$

is the standard error function. The argument of the logarithmic term differs from the usual Coulomb logarithm ( $\ln \Lambda$ ) and can be obtained by using the quantum-mechanical minimum impact parameter for electrons incident on plasma electrons. ${ }^{13}$ The parameters $\mathrm{n}_{\mathrm{ep}}, \mathrm{T}_{\mathrm{ep}}$ represent the density and temperature of the toroidal core electrons, and $\mathrm{T}_{A}$ is the kinetic energy of the annulus electrons. Because $\mathrm{T}_{\text {ep }}$ and $\mathrm{T}_{\mathrm{A}}$ are approximately $0.4 \mathrm{keV}$ and $200 \mathrm{keV}$, respectively, for the EBT-I experiment, $\Phi(R) \cong 1$ since $R \gg 1$. Our neglect of high-order terms in ( $\left.k T_{e p} / m_{e} c^{2}\right)$ is based on the fact that for electrons, $\mathrm{m}_{\mathrm{e}} \mathrm{c}^{2}=511 \mathrm{keV}$. Under these conditions, a simplified form for Eq. (3.1.1) can be written as

$$
\frac{d E}{d t} \cong-\frac{2 \pi e^{4} n_{e p}}{m_{e} c} \frac{\gamma^{2}}{\sqrt{\gamma^{2}-1}} \ln \left(\frac{{ }^{n \omega}{ }_{p e}}{k T_{e p}}\right)^{2}
$$

In mks units, with $\mathrm{T}$ in $\mathrm{keV}, \mathrm{Eq} .(3.1 .5)$ becomes

$$
\frac{\mathrm{dE}}{\mathrm{dt}}\left(\frac{\mathrm{W}}{\text { electron }}\right) \cong 1.22 \times 10^{-33} \ln \left(1.38 \times 10^{-33} \frac{\mathrm{n}_{\mathrm{ep}}}{\mathrm{T}_{\mathrm{ep}}^{2}}\right)^{-1} \frac{\gamma^{2}}{\sqrt{\gamma^{2}-1}} \mathrm{n}_{\mathrm{ep}} \cdot(3.1 .6)
$$


If there are a total of $\mathrm{n}_{\mathrm{A}} \mathrm{V}_{\mathrm{A}} \mathrm{N}$ relativistic electrons, the microwave power level required to compensate for the drag losses is given by

$$
\begin{aligned}
P_{\mathrm{drag}}(W) \cong\left[1.22 \times 10^{-33} \ln \left(1.38 \times 10^{-33} \frac{\mathrm{n}_{\mathrm{ep}}}{\mathrm{T}_{\mathrm{ep}}^{2}}\right)^{-1}\right. \\
\left.\times \frac{\gamma^{2}}{\sqrt{\gamma^{2}-1}} \mathrm{n}_{\mathrm{A}} \mathrm{n}_{\mathrm{ep}}\right] \mathrm{V}_{\mathrm{A}} \mathrm{N}
\end{aligned}
$$

It is interesting to note the relative insensitivity of the above natural logarithmic term which varies by $<8 \%$ (from 32- 35), extrapolating from the present EBT-I experiment to possible EBT reactor parameters. Choosing 32.5 as a characteristic value, Eq. (3.1.7) reduces to

$$
P_{\mathrm{drag}} \cong\left(4 \times 10^{-32} \frac{\gamma^{2}}{\sqrt{\gamma^{2}-1}} n_{A} n_{e p}\right) V_{A^{N}}
$$

The dependence of the drag losses on both the core and annulus densities and the ring plasma volume is apparent, in addition to the important relativistic term $\gamma^{2} / \sqrt{\gamma^{2}-1}$ that scales as $\gamma$ for very relativistic electrons. A comprehensive experimental examination of the annulus stability boundaries is planned for EBT-S and will help to establish the acceptable range for the ratio of cold-to-hot plasma density required for ring stabilization. By defining a "ring stability ratio" as

$$
\mathrm{f}_{\mathrm{R}} \equiv \frac{\mathrm{n}_{\text {cold }}}{\mathrm{n}_{\text {hot }}} \cong \frac{\mathrm{n}_{\mathrm{ep}}}{\mathrm{n}_{\mathrm{A}}}
$$

one can write the following compact expression for the drag power loss:

$$
P_{\operatorname{drag}}(W) \cong\left(4 \times 10^{-32} \mathrm{f}_{\mathrm{R}} \frac{\gamma^{2}}{\sqrt{\gamma^{2}-1}} \mathrm{n}_{\mathrm{A}}^{2}\right) \mathrm{V}_{\mathrm{A}} \mathrm{N}
$$




\subsection{Application of Drag Cooling Model to EBT-I Data}

Does drag cooling of the ring electrons on the toroidal core plasma agree with the experimental estimates of the microwave power going to the annulus? For EBT-I (see Table 2.1) with $\mathrm{T}_{\mathrm{A}}=200 \mathrm{keV}, \mathrm{n}_{\mathrm{A}}=5 \times$ $10^{17} / \mathrm{m}^{3}$, $\mathrm{n}_{\text {ep }}=1.5 \times 10^{18} / \mathrm{m}^{3}$, and $\mathrm{v}_{\mathrm{A}} \cong 0.06 \mathrm{~m}^{3}$, Eq. (3.1.8) indicates

that $P_{\text {drag }}=3.6 \mathrm{~kW}$. Our earlier estimates for $P_{\text {synch }}$ and $P_{\text {scatt }}$ indicated a combined power loss of $\sim 0.64 \mathrm{~kW}$, giving a total annulus power requirement of $4.24 \mathrm{~kW}$, which is approximately $50 \%$ of the experimental estimate of $9.6 \mathrm{~kW}$. This factor of 2 discrepancy between theory and experiment can be attributed to the actual drag equation itself, based on binary collision theory and a test particle treatment of the hot electrons. It is conceivable that this factor of 2 can be recovered if a relativistic or full Maxwellian distribution is used for the rings.

It is interesting to note here, however, that stable annulus decay times as long as $0.23 \mathrm{sec}$ have been experimentally measured (see Fig. 1). If the stored energy corresponding to this decay time is also on the order of $\sim 40 \mathrm{~J} /$ sector, ${ }^{2}$ then the experimental estimate for $\mathrm{P}_{\mu \mathrm{A}}$ would be lowered to

$$
\mathrm{P}_{\mu \mathrm{A}} \cong \frac{40 \mathrm{~J} / \mathrm{sector}}{0.23 \mathrm{sec}} \times 24 \text { sectors } \cong 4.2 \mathrm{~kW} \text {, }
$$

indicating very good agreement with theory. 
PHOTO 2705A-74

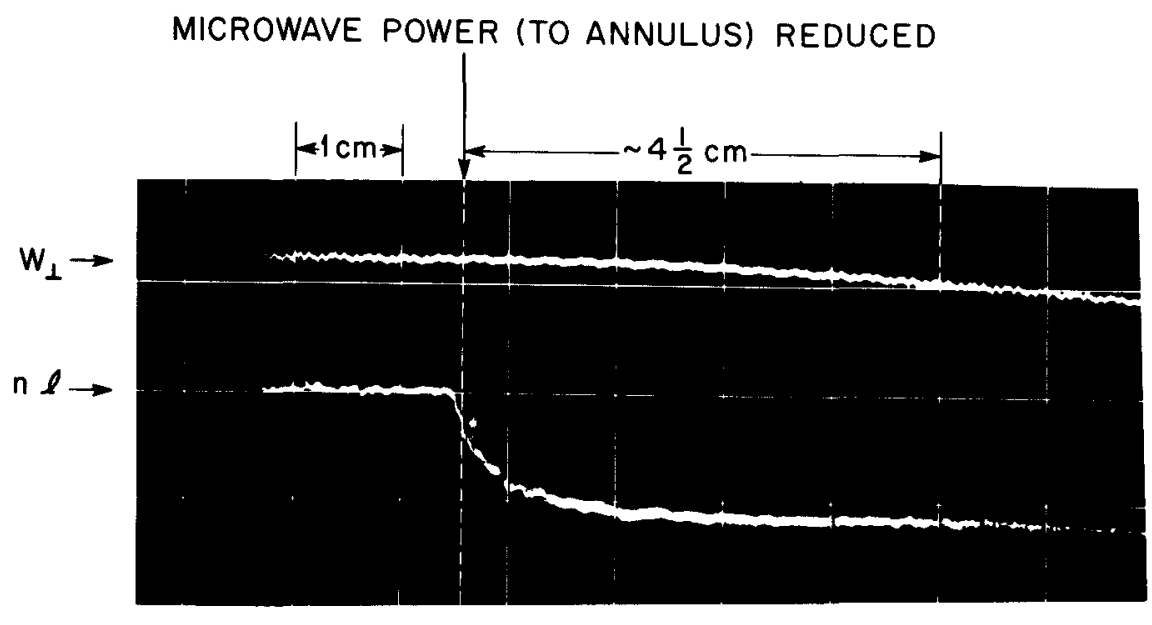

$50 \mathrm{msec} / \mathrm{cm}$

Fig. 1. Tracing of decays of $W_{\perp}$ (measured with diamagnetic 1oop) and $\mathrm{n}_{\mathrm{e}}{ }^{\ell}$ (measured with interferometer) following a reduction of microwave power; the horizontal scale is $50 \mathrm{msec} / \mathrm{cm}$. 


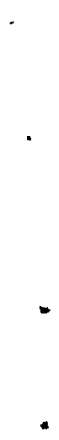




\section{ANNULUS MICROWAVE POWER SCALING}

Because the core-stabilizing electron annulus must be continuously driven by the microwave sources during steady state operation, the question of power drain from the annulus is extremely important in scaling the microwave power requirements. In its most basic form, the annulus power balance is given by

$$
P_{\mu A}=P_{\text {synch }}+P_{\text {brems }}+P_{\text {scatt }}+P_{\text {drag }}
$$

where $\mathrm{P}_{\text {synch }}$ and $\mathrm{P}_{\text {brems }}$ represent power lost by synchrotron and bremsstrahlung radiation, $\mathrm{P}_{\text {scatt }}$ is the scattering loss due to annulus electron-electron Coulomb collisions, $\mathrm{P}_{\mathrm{drag}}$ represents the power lost from the relativistic electrons due to drag on the toroidal core electrons, and $\mathrm{P}_{\mu \mathrm{A}}$ is the microwave power required to sustain the annulus. In terms of plasma and machine parameters, Eq. (4.1) can be expressed as follows in mks units:

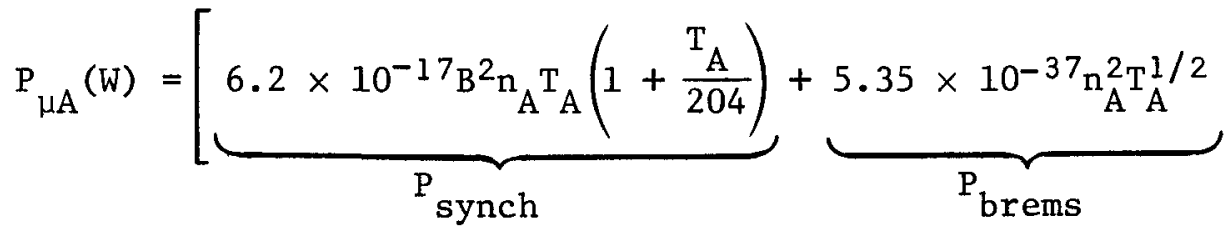

$$
\begin{aligned}
& +\underbrace{2.2 \times 10^{-32} \frac{\mathrm{n}_{\mathrm{A}}^{2} \ln \Lambda_{\text {ee }}}{\mathrm{T}_{\mathrm{A}}^{1 / 2}}}_{\mathrm{P}_{\text {scatt }}}+1.22 \times 10^{-33} \ln \\
& \times \underbrace{\left(1.38 \times 10^{-33} \frac{\mathrm{n}_{\text {ep }}}{\mathrm{T}_{\text {ep }}^{2}}\right)^{-1} \frac{\gamma^{2}}{\sqrt{\gamma^{2}-1}} \mathrm{n}_{\mathrm{A}^{\mathrm{n}} \mathrm{ep}}}_{\text {drag }}] \mathrm{V}_{\mathrm{A}^{\mathrm{N}}},
\end{aligned}
$$

where $T$ is in $k e V$ and $\ln \Lambda_{e e}=24-\ln \left(\sqrt{10^{-6} \mathrm{n}_{A}} / 10^{3} \mathrm{~T}_{\mathrm{A}}\right), \gamma=1+\mathrm{T}_{\mathrm{A}} / 511$, $\mathrm{V}_{\mathrm{A}}$ is the annulus volume per mirror sector defined previously, and $\mathrm{N}$ is 
the total number of mirror sectors. From the definition of plasma beta, we can write the regional plasma density as

$$
n_{j}=\frac{\beta_{j} B_{j}^{2}}{2 \mu_{0}\left(k T_{j}\right)} ; \quad j=A, c \text { for annulus and core, }
$$

where the magnetic field strength in the vicinity of the annulus is evaluated at the profile heating frequency $\left(\mathrm{B}_{\mathrm{A}}=\mathrm{B}_{\mu \mathrm{p}}\right)$, while in the core it is set at the midplane value $\left(B_{c}=B_{m i d}\right)$. Using $n_{j}$, Eq. (4.2) can be rewritten in terms of annulus beta and magnetic field to obtain

$$
\begin{aligned}
P_{\mu A}(W) & \cong\left[1.54 \times 10^{5} \beta_{A} B_{\mu p}^{4}\left(1+\frac{T_{A}}{204}\right)\right. \\
& +3.3 \times 10^{6} \frac{\beta_{A}^{2} B_{\mu p}^{4}}{T_{A}^{3 / 2}}+1.36 \times 10^{11} \frac{\beta_{A}^{2} B_{\mu p}^{4} \ln \Lambda_{e e}}{T_{A}^{5 / 2}} \\
& +1.47 \times 10^{7} \ln \left(1.38 \times 10^{-33} \frac{n_{e p}}{T_{e p}^{2}}\right)^{-1} \frac{\gamma^{2}}{\sqrt{\gamma^{2}-1}} \\
& \left.\times \frac{\mathrm{f}_{A} \beta_{A}^{2} B_{\mu p}^{4}}{(\gamma-1)\left(T_{e}+T_{i}\right)_{c}}\right] V_{A}{ }^{N} .
\end{aligned}
$$

The parameter $\mathrm{f}_{\mathrm{A}}$ is defined by

$$
E_{A} \equiv \frac{\beta_{C} B_{m i d}^{2}}{\beta_{A} B_{\mu p}^{2}}
$$

and is used to quantify the comparability of the toroidal core beta to that of the annulus beta, each of which is evaluated in a different region of magnetic field strength (e.g., $\mathrm{f}_{\mathrm{A}}=7.55 \times 10^{-3}$ for EBT-I with $B_{c}=0.15 \%$ and $B_{\text {mid }}=0.45 \mathrm{~T}$ ). For a specified profile heating 
frequency, Eq. (4.3) indicates the power level requirements to sustain a desired annulus beta, given a particular set of toroidal core plasma parameters.

Confidence in the predicted value of $\mathrm{P}_{\mu \mathrm{A}}$ depends, however, on an accurate measurement of the total annulus volume $\left(V_{A} N\right)$, which at present is still a vague quantity. Based on experimental measurements ${ }^{2,5}$ and theoretical estimates, it appears that a range exists for the annulus thickness, $\delta_{A}$, which varies between a minimum value of the relativistic electron gyrodiameter and a maximum of $23-4 \mathrm{~cm}$ as measured on ELMO. 8 Because a relativistic electron in the annulus has a gyroradius given by

$$
\mathrm{r}_{\text {gyro }}(\mathrm{m})=1.71 \times 10^{-3} \frac{\sqrt{\gamma^{2}-1}}{\mathrm{~B}_{\mu \mathrm{p}}}
$$

one can write a general expression for the annulus volume per sector as

$$
\mathrm{V}_{\mathrm{A}} \cong 2 \pi \mathrm{a}_{\mathrm{p}} \cdot \delta_{\mathrm{A}} \cdot \mathrm{L}_{\mathrm{A}} \cong 2.15 \times 10^{-2} \frac{\sqrt{\gamma^{2}-1}}{\mathrm{~B}_{\mu \mathrm{p}}} \mathrm{f}_{\mathrm{E}} \cdot \mathrm{a}_{\mathrm{p}} \cdot \mathrm{L}_{\mathrm{A}} \text {, }
$$

where $f_{E}$ is a "thickness enhancement factor," which allows for annuli thicknesses larger than the diameter of a relativistic electron orbit (e.g., $f_{E} \cong 2.9$ for $E B T-I$ which gives an annulus thickness, $\delta_{A} \cong 2.5 \mathrm{~cm}$ ). Utilizing this result in Eq. (4.3), one obtains an explicit form for $P_{\mu A}$ that is given by

$$
\begin{aligned}
& \mathrm{P}_{\mu \mathrm{A}}=\left[1.54 \times 10^{5} \beta_{\mathrm{A}}\left(1+\frac{\mathrm{T}_{\mathrm{A}}}{204}\right)+3.3 \times 10^{6} \frac{\mathrm{B}_{\mathrm{A}}^{2}}{\mathrm{~T}_{\mathrm{A}}^{3 / 2}}\right. \\
& +1.36 \times 10^{11} \frac{\beta_{A}^{2} \ln \Lambda_{e e}}{T_{A}^{5 / 2}}+1.47 \times 10^{7} \ln \left(1.38 \times 10^{-33} \frac{\mathrm{n}_{\mathrm{ep}}}{\mathrm{T}_{\mathrm{ep}}^{2}}\right)^{-1} \\
& \left.\times \frac{\gamma^{2}}{\sqrt{\gamma^{2}-1}} \frac{\mathrm{f}_{\mathrm{A}} \beta_{\mathrm{A}}^{2}}{(\gamma-1)\left(\mathrm{T}_{\mathrm{e}}+\mathrm{T}_{\mathrm{i}}\right)_{\mathrm{c}}}\right]\left(2.15 \times 10^{-2} \sqrt{\gamma^{2}-1} \mathrm{f}_{\mathrm{E}} \cdot \mathrm{a}_{\mathrm{p}} \cdot \mathrm{L}_{\mathrm{A}}\right) \\
& \times \mathrm{B}_{\mu \mathrm{p}}^{3} \mathrm{~N}
\end{aligned}
$$


Because our previous estimates for EBT-I have indicated negligible bremsstrahlung and only small losses due to synchrotron radiation and electron-electron scattering ( $P_{\text {synch }}+P_{\text {scatt }} \cong 0.6 \mathrm{~kW}$ ), it appears that the microwave power required to sustain the rings in EBT-I scales as the drag loss, i.e.,

$$
\left.P_{\mu A}\right|_{E B T-I} \cong 10^{7} \frac{\gamma^{2}}{\sqrt{\gamma^{2}-1}} \frac{\mathrm{f}_{A} \mathrm{f}_{E} \beta_{A}^{2} a_{p} L_{A}}{\left(T_{e}+T_{i}\right)_{c}} B_{\mu p}^{3} N
$$

This scaling is also anticipated for EBT-S, although the projected factor of 2 increase in the core plasma density $\left(n_{e p} \propto B^{2}\right)$ will require further increases in microwave power due to enhanced drag cooling. For the higher magnetic fields planned for future devices, synchrotron radiation will also become important, especially since annulus temperatures in the vicinity of $1 \mathrm{MeV}$ will be required to simultaneously demonstrate high annulus beta $(\sim 40 \%)$ and significant core plasma densities (n ep $\gtrsim 5 \times 10^{13} / \mathrm{cm}^{3}$ ). A simple scaling law (including both synchrotron radiation and drag losses) appropriate for use in optimization studies can be written as follows:

$$
\begin{aligned}
& \mathrm{P}_{\mu \mathrm{A}} \cong\left\{3.17 \times 10^{-14} \mathrm{~B}_{\mu \mathrm{p}}^{2} \mathrm{n}_{\mathrm{A}}(\gamma-1)[1+2.5(\gamma-1)]\right. \\
& \left.+4.0 \times 10^{-32} \frac{\gamma^{2}}{\sqrt{\gamma^{2}-1}} n_{A^{n}}{ }_{e p}\right\} V_{A^{N}} \text {, }
\end{aligned}
$$

where

$$
\gamma=1+\frac{\mathrm{T}_{\mathrm{A}}(\mathrm{keV})}{511}
$$




\section{APPLICATIONS AND DISCUSSION}

In view of the reasonably good agreement between the experimental and theoretical estimates of $\mathrm{P}_{\mu \mathrm{A}}$ for $E B T-I$, there is an immediate interest in determining the necessary annulus power requirements for upcoming scaling studies on EBT-S. Such an assessment could be vital to the EBT-P device for two reasons. In the near term, it may provide valuable sizing information pertaining to the fraction of the system power necessary to drive the microwave sources. These estimates may also benefit the ongoing development program for millimeter wavelength, cw microwave sources by assuring their procurement at sufficiently high power levels. On the longer time scales envisioned for an EBTR, the continuous microwave power required to sustain the annulus during steady state operation may become the determining factor for overall reactor efficiency. This is to be expected since following ignition, the bulk heating (either ECH or neutral beams) will be terminated and the plasma temperature maintained by alpha particle heating and collisional energy gains from the annulus.

In anticipation of the enhanced drag cooling to be encountered during EBT-S operation, scaling curves have been devised for both EBT-I and EBT-S, enabling us to examine the sensitivity of the annulus electron temperature as a function of core plasma density for various microwave power levels. These curves are based on the annulus power balance given by Eq. (4.2) and assume values for the annulus density, volume, and magnetic field strength consistent with those found in Table 2.1 and the Appendix.

\subsection{Comparison of Theory to ELMO and EBT-I}

The EBT-I scaling curves shown in Fig. 2 indicate the maximum annulus electron temperatures that can be maintained against drag losses for a given microwave power level. The different power input levels are shown in units of $\mathrm{W} / \mathrm{sector}$ in order to provide a means of comparison between the experimental data available for the single mirror ELMO device and the full 24-mirror EBT-I experiment (the total annulus power requirements for the complete torus are also indicated). For each of 


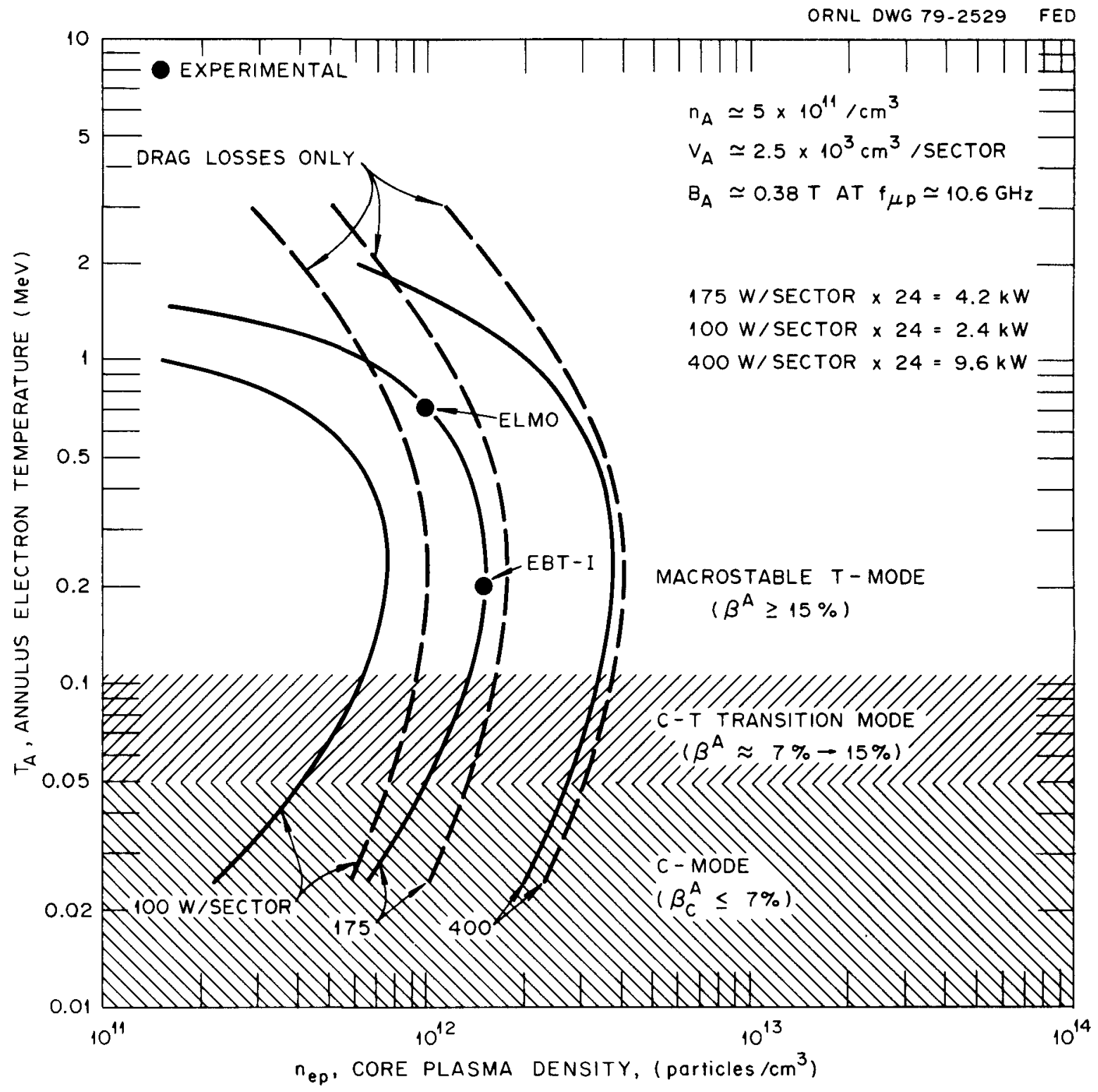

Fig. 2. EBT-I - annulus electron temperature vs core plasma density. 
the three power levels Indicated, two sets of curves are presented: (1) the dashed curves showing the cooling of the annulus electron temperature due to drag losses alone and (2) the solid curves (to be referred to as the "total loss" curves), which take into account the additional energy loss due to synchrotron radiation and annulus electronelectron scattering. Bremsstrahlung is smaller than the least of these by better than two orders of magnitude and is therefore neglected in the "total loss" curves.

In looking at the "drag cooling" curves first, the two most important features to be cognizant of are the following:

(1) for a given annulus power input, there is a dramatic decrease in the ring temperature for increasing levels of core plasma density; and

(2) the ability to maintain annulus ring temperatures at values consistent with high annular beta $\left(\beta_{A} \gtrsim 30 \%\right)$ will require increased amounts of microwave power in going to higher core densities because $\mathrm{P}_{\mu \mathrm{A}} \propto \mathrm{n}_{\text {ep }}$ in accordance with Eq. (3.1.8). This second point is illustrated in Fig. 2 by noting that for a fixed annulus temperature of $200 \mathrm{keV}$, a factor of 4 increase in the core plasma density can be realized by increasing the total microwave power from 2.4 to $9.6 \mathrm{~kW}$. This increase in density assumes, of course, that there has been the necessary enhancement in magnetic field strength needed to support such an increase. If we go now to the "total loss" curve, one sees that for the same power level and a particular core density, there is further cooling of the ring temperature attributed to synchrotron radiation and annulus electron-electron scattering. For the actual EBT-I experiment, this additional deterioration in the annulus energy confinement time determines the limiting value for maximum core density which can be maintained without causing excessive cooling and possible disruption of the annulus. For the plasma and machine parameters considered, this density reduction appears to be $\sim 20 \%$ at $200-\mathrm{keV}$ annulus temperatures, and $\mathrm{P}_{\mu \mathrm{A}}=4.2 \mathrm{~kW}$. In the transition from lower to higher power levels, this variation in achievable core density between the "total loss" and "drag cooling" curve becomes less pronounced. This 
is as expected, however, because at high core densities, drag losses completely dominate the annulus power balance and the two curves begin to coalesce. This effect should be much more apparent as one goes to the more desirable operating regimes anticipated in future devices.

Figure 2 also illustrates the correlation between values of annular beta and the various modes of operation observed in the EBT device. The lowest cross-hatched portion of the curve (10 keV $\left.\mathrm{T}_{\mathrm{A}} \lesssim 50 \mathrm{keV}\right)$ corresponds to the cold, noisy C-mode of operation in which the annular beta values are $<7 \%$. As one goes to higher ring temperatures in the range of $50-100 \mathrm{keV}\left(\beta_{A} \cong 7-15 \%\right)$, there is a transition from this $C$-mode to the quiet, macrostable T-mode. For annulus electron temperatures $>110 \mathrm{keV}$, one obtains substantial annular beta values that ensure the production of a well-defined minimum in the magnetic field [field reversal $\left(\beta_{A} \gtrsim 1\right)$ also appears possible in Fig. 2 for $\mathrm{B}_{\mathrm{A}} \cong 0.38 \mathrm{~T}$ and $\left.\mathrm{T}_{\mathrm{A}} \gtrsim 720 \mathrm{keV}\right]$. By delineating the unfavorable modes of operation from the desired T-mode, it is possible that scaling curves such as Fig. 2 can be used to establish credible regions of annulus parameter space given a set of desired core parameters and a certain microwave power level.

In comparing the two sets of curves shown in Fig. 2, one immediately notices that substantial perturbations exist between the two at the high and low temperature ends of the scaling curves. In the cold and transition modes, this divergence is due to increased collisionality among the annulus electrons that result in enhanced scattering losses at lower temperatures. More important, however, is the accelerated ring cooling occurring at the high temperature end due to synchrotron radiation. In contrast to scattering losses, which are minimal in the T-mode, synchrotron radiation can produce losses comparable to drag provided the magnetic fields are large and annulus temperatures are $>1 \mathrm{MeV}$. Although the typical EBT-I experimental point shows synchrotron losses to be small compared to drag, ELMO data indicate that synchrotron radiation does significantly affect the power balance.

Finally, we would be remiss in our discussion if we did not point out the reasonably good agreement shown between theory and typical experimental data for ELMO and EBT-I. This conformity at the $175 \mathrm{~W} /$ sector power level helps to substantiate our earlier explanation regarding the 
apparent discrepancy between theory and experiment (Sect. 3.2), since an input of $400 \mathrm{~W} /$ sector would have produced annulus temperatures 5-6 times higher than those observed in EBT-I. Such results are clearly evident in looking at Fig. 2. In all fairness, however, it should be emphasized that there is a degree of uncertainty in the ELMO experimental data (discussed in Sect. 2) which will result in its deviation from the experimental curve. One possible source for this deviation is the larger magnetic fields $\left(B_{A} \sim 0.7 \mathrm{~T}\right.$ ) (Ref. 10) found in ELMO. The enhanced synchrotron radiation requires a modest increase in the annulus power from $\sim 175 \mathrm{~W} /$ sector to $\sim 250 \mathrm{~W} /$ sector, but it is still in fairly good agreement with theory. Due to this lack of firm data, experimental measurements should be planned for EBT to specifically address this question of drag cooling. Actual measurements of the annulus temperature as a function of core density could provide valuable data points for Fig. 2 necessary to confirm or refute drag as an important loss mechanism. For example, Fig. 2 indicates that by operating EBT in its initial EBT-I configuration, it should be possible to observe a five-fold decrease in annulus temperatures, from $1 \mathrm{MeV}$ to $200 \mathrm{keV}$, by varying the core density within a factor of $\sim 2$ (from $\sim 6.5 \times 10^{11} / \mathrm{cm}^{3}$ to $1.5 \times 10^{12} / \mathrm{cm}^{3}$ ).

\subsection{Scaling Projections for EBT-S}

By utilizing higher microwave frequencies and power levels, EBT-S operation will focus on achieving higher density and temperature plasma parameters needed to test confinement scaling. Present plans call for a multiplication in the magnetic field strength over that of EBT-I by a factor of $w \sqrt{2}$. According to EBT density scaling $\left(n \propto B^{2}\right)$, this should allow operation with increased core densities in the vicinity of $v 4 \times$ $10^{12} / \mathrm{cm}^{3}$. Such improved core performance characteristics are expected to lead to further growth in the annulus power requirements due to the linear dependence of drag losses on the core density.

The appropriate scaling curves for EBT-S, showing "total loss" and power level projections, are presented in Fig. 3. A noticeable feature of these particular scaling curves is the upward shift in the temperature boundary for the various modes. This need to go to higher annulus 


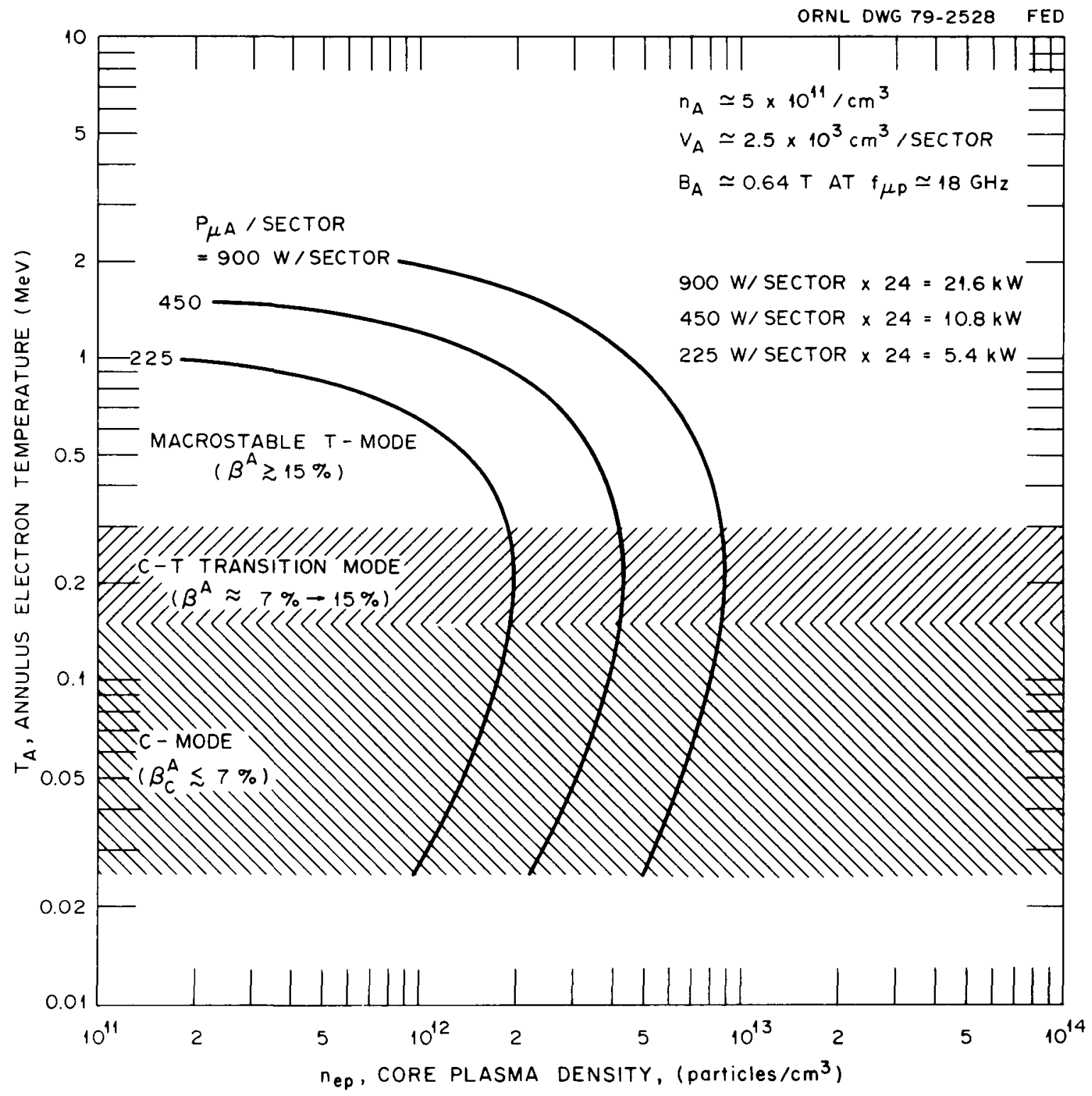

Fig. 3. EBT-S - annulus electron temperature vs core plasma density. 
temperatures $\left(\mathrm{T}_{\mathrm{A}} \gtrsim 300 \mathrm{keV}\right)$ in order to reach the macrostable $\mathrm{T}$-mode, is dictated by the increasing fields and ring stability requirements $\left(\mathrm{n}_{\text {cold }} / \mathrm{n}_{\text {hot }}>1\right)$. Despite these increasing temperatures, drag still surpasses synchrotron radiation as the predominant energy drain for EBT-S. This can be seen upon closer inspection of Fig. 3. As indicated,

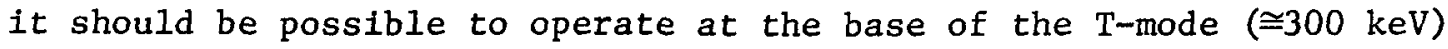
with a core density, $\mathrm{n}_{\mathrm{ep}} \cong 4 \times 10^{12} / \mathrm{cm}^{3}$ and $\mathrm{P}_{\mu \mathrm{A}} \lesssim 10.8 \mathrm{~kW}$. However, in order to reach annular betas comparable to EBT-I ( $28 \%)$, operation at this elevated core density will require annulus temperatures $\gtrsim 560 \mathrm{keV}$ and a power level of $\sim 520 \mathrm{~W} /$ sector $\left(P_{\mu \mathrm{A}} \cong 12.5 \mathrm{~kW}\right)$. This factor of 3 multiplication in power over that of EBT-I is due mainly to the increased drag losses $\left[\propto_{A} n_{e p} \gamma^{2} /\left(\sqrt{\gamma^{2}-1}\right)\right]$ postulated for EBT-S.

Before concluding our discussion of EBT-S results, a final topic remains to be addressed regarding the confidence level of these results. Because our earlier theoretical estimates for EBT-I seemed to underpredict the experimental power requirements by a factor of $\sim 2$, it is logical to ask if our present EBT-S projections are low by this same multiple. A preliminary comparison between theory and the initial experimental measurements performed on EBT-S indicates that this factor of 2 discrepancy also exists on EBT-S. This can be shown roughly by the following example. If one assumes that the annulus in EBT-S absorbs roughly the same amount of applied power ( $26 \%$ ) as in EBT-I, ${ }^{2}$ then the total microwave power $\left(\mathrm{P}_{\mu}\right)$ required to sustain the various plasma components can be written as

$$
P_{\mu}=\frac{P_{\text {core }}+P_{\mu A}+P_{\text {surf }}}{1-\alpha} \cong \frac{P_{\mu A} / 26 \%}{1-\alpha},
$$

where $\alpha$ is the fraction of power lost during transmission $(\alpha=0.35$ in EBT-I). For annular beta ranging from $\sim 15-30 \%$ and core densities of $22.5 \times 10^{12} / \mathrm{cm}^{3}, 14 \mathrm{Fig} .3$ indicates $P_{\mu \mathrm{A}} \cong 7.0$ and $9.0 \mathrm{~kW}$, respectively. If these are indeed the power levels required to sustain the annulus in EBT-S, then Eq. (5.2.1) indicates that the total microwave system power will vary from $\sim 40 \mathrm{~kW}$, for operation at the base of the T-mode, to $\sim 50 \mathrm{~kW}$ for $\beta_{A} \cong 30 \%$. This $40-\mathrm{kW}$ power level appears to be a factor of 2 
lower than the measurements made on EBT-S, in which annulus formation was observed at a microwave power leve1 of $\sim 80 \mathrm{~kW}$ for high density operation. 15

\section{ACKNOWLEDGMENTS}

The authors would like to thank B. G. Logan (Lawrence Livermore Laboratory) and N. H. Lazar (TRW Defense \& Space Systems, Inc.) for suggesting the possible importance of electron drag and its implications to the ELMO/EBT devices. We also wish to acknowledge the helpful discussions and continued support of $\mathrm{C}$. L. Hedrick and the useful comments and input from members of the ORNL experimental staffs ( $R$. J. Colchin, G. R. Haste, Jr., F. W. Baity, Jr., and J. L. Dunlap). 


\section{REFERENCES}

1. R. A. Dandl et a1., paper IAEA-CN-37/64, presented at 7 th Int. Conf. on Plasma Physics and Controlled Nuclear Fusion Research, Innsbruck, Austria, Aug. 23-28, 1978; Proc. 5th Int. Conf. on Plasma Physics and Controlled Nuclear Fusion Research, Vol. II, p. 141 (1975).

2. R. A. Dand 1 et al., Oak Ridge National Laboratory Reports ORNL/TM-6457 (October 1978) and ORNL-TM-4941 (June 1975).

3. D. B. Nelson and C. L. Hedrick, Nuc1. Fusion 19, 283 (1979).

4. R. A. Dandl et a1., Oak Ridge National Laboratory Report ORNL-TM-5451 (April 1976).

5. R. A. Dand1 et a1., Oak Ridge National Laboratory Report ORNL-TM-3694 (November 1971).

6. R. A. Dand1 et a1., Proc. 4th Int. Conf. on Plasma Physics and Controlled Nuclear Fusion Research, Vol. II, p. 607 (1971).

7. R. A. Dandl et al., Proc. 3rd Int. Conf. on Plasma Physics and Controlled Nuclear Fusion Research, Vol. II, p. 435 (1969).

8. W. B. Ard et al., Oak Ridge National Laboratory Report ORNL -4150 (September 1967).

9. Nucl. Fusion, Special Supplement 1973, World Survey of Major Facilities in Controlled Fusion Research-1973 Edition, IAEA, Vienna, pp. 249-250 (1973).

10. R. A. Dandl et a1., "E1ectron-Cyclotron Heating by 8-mm Microwave Power in the Magnetic Facility ELMO," p. 181 in Relativistic Plasma, ed. by O. Bruneman and W. B. Pardo, W. B. Benjamin, Inc., New York, 1968.

11. T. Kammash and D. L. Gailbraith, Nuc1. Fusion 13, 464 (1973).

12. T. Kammash, Fusion Reactor Physics - Principles and Technology, p. 131, Ann Arbor Science Publishers, 1975.

13. J. D. Jackson, Classical Electrodynamics, 2nd ed., p. 618, John Wiley \& Sons, Inc., New York, 1975.

14. F. W. Baity (Oak Ridge National Laboratory) private communication. 15. F. W. Baity (Oak Ridge National Laboratory) private communication. 
-

$\checkmark$ 
APPENDIX 
NOMINAL EBT PARAMETERS

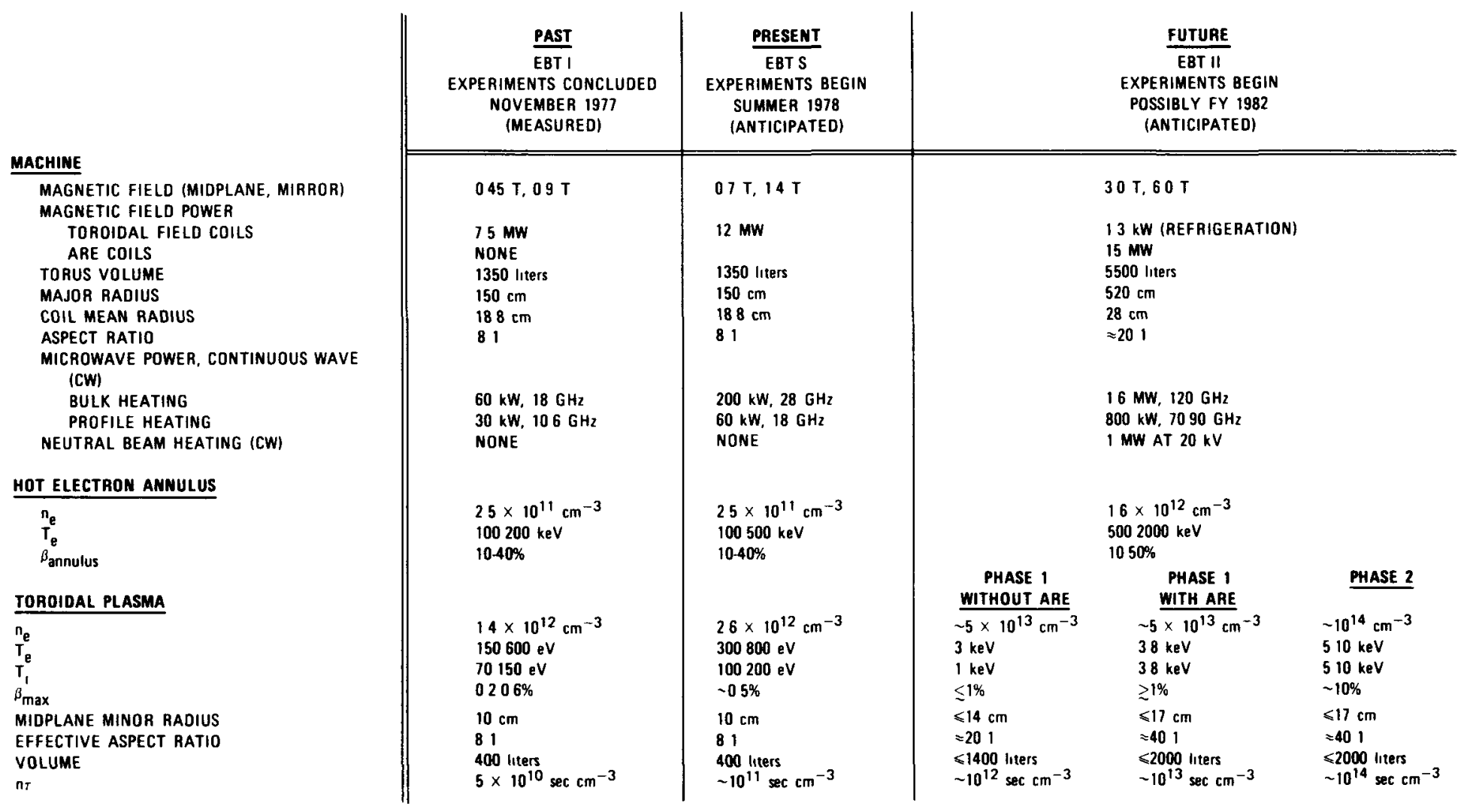


ORNL/TM-6910

Dist. Category UC-20a, d, g

INTERNAL DISTRIBUTION

1. L. A. Berry

2. A. L. Boch

3. J. D. Callen

4. R. A. Dory

5. E. F. Jaeger

6. T. Kammash

7. 0. B. Morgan

8. J. Sheffield

9. N. A. Uckan
11-31. S. K. Borowski

32-33. Laboratory Records Department 34. Laboratory Records, ORNL-RC 35. Document Reference Section

36-37. Central Research Library

38. Fusion Energy Division Library

39. Fusion Energy Division Communications Center

40. ORNL Patent Office

\section{EXTERNAL DISTRIBUTION}

41. D. J. Anthony, Energy Systems and Technology Division, Genera1 Electric Company, 1 River Road, Bldg. 23, Room 290, Schenectady, NY 12345

42. Bibliothek, Institute for Plasma Physics, 8046 Garching bei Minchen, Federal Republic of Germany

43. Bibliothèque, Service du Confinement des Plasmas, C.E.A., B.P. No. 6, 92, Fontenay-aux-Roses (Seine), France

44. Lung Cheung, Department of Electronics, University Science Center, The Chinese University of Hong Kong, Shatin, N.T., Hong Kong

45. F. Cap, University of Innsbruck, A-6020, Innsbruck, Austria

46. J. F. Clarke, Office of Fusion Energy, G-234, Department of Energy, Washington, DC 20545

47. R. W. Conn, Fusion Technology Program, Nuclear Engineering Department, University of Wisconsin, Madison, WI 53706

48. CTR Library, c/o Alan F. Haught, United Technologies Research Laboratory, East Hartford, CT 06108

49. CTR Reading Room, c/o Allan N. Kaufman, Physics Department, University of California, Berkeley, CA 94720

50. J. Narl Davidson, School of Nuclear Engineering, Georgia Institute of Technology, Atlanta, GA 30332

51. Documentation S.I.G.N., Départment de la Physique du Plasma et de la Fusion Controlée, Association EURATOM-CEA sur la Fusion, Centre d'Études Nucléaires, B. P. 85 Centre du Tri, 38041 Grenoble, Cedex, France

52. W. R. Ellis, Office of Fusion Energy, G-234, Department of Energy, Washington, DC 20545

53. G. A. Emmert, Nuclear Engineering Department, University of Wisconsin, Madison, WI 53706

54. Harold K. Forsen, Exxon Nuclear Co., Inc., 777 106th Avenue, N.E., C-000777, Bellevue, WA 98009 
55. H. P. Furth, Princeton Plasma Physics Laboratory, Princeton University, Forrestal Campus, P.0. Box 451, Princeton, NJ 08540

56. Roy W. Gould, California Institute of Technology, Mail Stop 116-81, Pasadena, CA 91125

57. C. R. Head, Office of Fusion Energy, G-234, Department of Energy, Washington, DC 20545

58. Robert L. Hirsch, Exxon Research and Engineering, P.0. Box 101, Florham Park, NJ 07932

59. Raymond A. Huse, Manager, Research and Development, Public Service Gas and Electric Company, 80 Park Place, Newark, NJ 07101

60. V. E. Ivanov, Physica1-Technical Institute of the Ukranian Academy of Sciences, 310108 Kharkov, U.S.S.R.

61. D. L. Jassby, Princeton Plasma Physics Laboratory, P.0. Box 451, Princeton, NJ 08540

62. A. Kadish, Office of Fusion Energy, G-234, Department of Energy, Washington, DC 20545

63. E. T. Karlson, Department of Technology, Box 534, S-75121 Uppsala, Sweden

64. Y. Kiwamoto, Research Institute for Energy Materia1s, Yokohama National University, Yokohama 232, Japan

65. R. N. Kostoff, Room 509, Office of Energy Research, Department of Energy, 401 First St., N.W., Washington, DC 20545

66 L. M. Kovrizhnykh, Lebedev Institute of Physics, Academy of Sciences of the U.S.S.R., Leninsky Prospect 53, Moscow, U.S.S.R.

67. Guy Lava1, Groupe de Physique Théorique, Ecole Polytechnique, 91 Palaiseau, Paris, France

68. Library, Centre de Recherches en Physique des Plasma, 21 Avenue des Bains, 1007, Lausanne, Switzerland

69. Library, Culham Laboratory, United Kingdom Atomic Energy Authority, Abingdon, Oxon, OX14 3DB, United Kingdom

70. Library, FOM-Institut voor Plasma-Fysica, Rijnhuizen, Jutphaas, Netherlands

71. Library, Institute for Plasma Physics, Nagoya University, Nagoya, Japan 464

72. Library, International Centre for Theoretical Physics, Trieste, Italy

73. Library, Laboratorio Gas Ionizzati, Frascati, Italy

74. J. G. Lominadze, Academy of Sciences of the Georgian S.S.R., 8 Dzerzhinski St., 38004, Tbilisi, U.S.S.R.

75. 0. P. Manley, Office of Fusion Energy, G-234, Department of Energy, Washington, DC 20545

76. D. G. McAlees, Exxon Nuclear Co., Inc., 777 106th Avenue, N.E., Bellevue, WA 98009

77. J. E. McCune, School of Engineering, Department of Aeronautics and Astronautics, Bldg. 37-391, Massachusetts Institute of Technology, Cambridge, MA 02139

78. A. T. Mense, Subcommittee on Energy Research and Production, B-374, Rayburn House Office Building, Washington, DC 20515

79. C. Mercier, Service du Theorie des Plasmas, Centre d'Etudes Nucléaires, Fontenay-aux-Roses (Seine), France

80. M. Murphy, Office of Fusion Energy, G-234, Department of Energy, Washington, DC 20545 
81. D. B. Nelson, Office of Fusion Energy, G-234, Department of Energy, Washington, DC 20545

82. K. Nishikawa, Institute for Fusion Theory, Hiroshima University, Higashisendamachi, Hiroshima, Japan

83. B. Outten, Jr., Western Metal Products Company, 1300 Weber Street, Orlando, FL 32803

84. R. E. Papsco, Grumman Aerospace Corp., 101 College Road, Princeton, NJ 08540

85. 0. Petrus, Supervisor, C.T.R., Theory Group, P1asma Physics Laboratory, "Alexandru Ion Cuza," University, Iasi, Romania, 6600

86. D. Pfirsch, Institute for P1asma Physics, 8046 Garching bei München, Federal Republic of Germany

87. Plasma Physics Library, c/o Dr. Philip Rosenau, Department of Mechanical Engineering, Technion-Israel, Institute of Technology, Haifa, Israel

88. Plasma Physics Group, Department of Engineering Physics, Australian National University, P.0. Box 4, Canberra A.C.T. 2600, Australia

89. A. Rogister, Institute for Plasma Physics, KFA, Postfach 1913, D-5170, Jülich 1, Federal Republic of Germany

90. W. Sadowski, Office of Fusion Energy, G-234, Department of Energy, Washington, DC 20545

91. V. D. Shafranov, I. V. Kurchatov Institute of Atomic Energy, 46, U1itsa Kurchatova, P.0. Box 3402, Moscow, U.S.S.R.

92. Yu. S. Sigov, Institute of Applied Mathematics of the U.S.S.R. Academy of Sciences, Miuskaya, Sq. 4, Moscow A-47, U.S.S.R.

93. W. M. Stacey, Jr., School of Nuclear Engineering, Georgia Institute of Technology, Atlanta, GA 30332

94. L. D. Stewart, Princeton Plasma Physics Laboratory, P.0. Box 451, Princeton, NJ 08540

95. J. B. Taylor, Culham Laboratory, United Kingdom Atomic Energy Authority, Abingdon, Oxon, 0X14 3DB, United Kingdom

96. Thermonuclear Library, Japan Atomic Energy Research Institute, Tokai, Naka, Ibaraki, Japan

97. K. Uo, Plasma Physics Laboratory, Kyoto University, Gokasho, Uji, Kyoto, Japan

98. Francisco Verdaguer, Director, Division of Fusion, Junta de Energia Nuclear, Madrid 3, Spain

99. K. M. Zwilsky, Office of Fusion Energy, G-234, Department of Energy, Washington, DC 20545

100. Office of Assistant Manager, Energy Research and Development, Department of Energy, Oak Ridge Operations Office, Oak Ridge, TN 37830

101-345. Given distribution as shown in TID-4500, Magnetic Fusion Energy (Distribution Category UC-20 a, d, g: Plasma Systems, Fusion Systems, and Theoretical Plasma Physics) 